\title{
Pemanfaatan Limbah Kulkas Dan Tabung Freon Untuk Membuat Kompressor
}

\author{
Azmi \\ Program Studi Teknik Industri \\ Jl. Utama Karya Bukit Batrem II Dumai \\ Email: azmi.omy@gmail.com
}

\begin{abstract}
ABSTRAK
Banyak pabrik yang memproduksi kompresor untuk dijual dipasaran, namun harga yang ditawarkan cukup tinggi yaitu mulai dari $\mathrm{Rp} 1.500 .000,-$. Dilihat dari fungsinya, kompresor buatan pabrik juga memiliki kelemahan yaitu jika ada kerusakan, ketersediaan suku cadang buatan pabrik yang sulit didapatkan dan harga suku cadang yang mahal. Berdasarkan dari permasalahan tersebut penelitian ini akan membuat kompresor dengan memanfaatkan limbah kulkas dan Tabung Freon untuk dijadikan kompresor dimana sumber utamanya menggunakan kompresor dari kulkas sebagai pengisi udara bertekanan sehingga menghasilkan udara bertekanan didalam tabung yang dapat digunakan untuk pemanfaatan service $\mathrm{AC}$ alat elektronik dan penggunaan rumah tangga. Pemanfaatan limbah kulkas dan tabung Freon ini sangat cocok digunakan untuk pemakaian pekerjaan yang memerlukan angin, selain bodinya ringan, hemat listrik dan aman dari jangkauan anak-anak. kompresor yang dirancang tekanan anginnya 120 Psi atau 8 bar, dengan kapasitas 8 bar dapat mengisi ban sepeda Motor bebek 3 Unit, Metic 3 Unit dan Sepeda 13 Unit, Lama waktu pengisian 8 bar adalah 10 Menit 11 detik. dan kompresor ini bisa diatur tekanan anginnya sesuai yang diinginkan oleh pengguna, tinggi kompresor ini $65 \mathrm{Cm}$, panjang $38 \mathrm{Cm}$ dan lebar $28 \mathrm{Cm}$ dengan harga jual satu unit alat kompresor yang dibuat seharga Rp. 930.000,-.
\end{abstract}

Kata kunci: Air Conditioner, Kompresor, Tabung freon.

\begin{abstract}
Many factories that manufacture compressors for sale over the counter, but the price is high enough that is has to offer starting from Rp 1.5 million. Seen from the function, the compressor also features factory-made drawbacks i.e. If there is damage, the availability of factory-made parts are difficult and the prices obtained spare parts are expensive. Based on the research of these problems will make the compressor by making use of waste refrigerators and Freon Tubes to be used as the main source where the compressor using the compressor of a refrigerator pressurized air as filler so that produces air pressure inside the tube that can be used to service utilization of AIR CONDITIONING electronics and household use. Utilization of waste refrigerators and Freon tubes is very suitable for the use of work that entails wind, in addition bodinya lightweight, efficient electricity and safely out of reach of children. Compressors designed wind pressure of 120 Psi or 8 bar, with a capacity of 8 bar can fill 3 duck motorcycle tires Unit, 3 units and bike Metic 13 units, Long charging time 8 bar is 10

UNITEX Vol 11 No.1 Januari - Juni 2018 p-ISSN 2089-3957 | e-ISSN 2580-2585
\end{abstract}


minutes 11 seconds. This compressor and pressure of wind can be arranged as desired by the user, high compressor is $65 \mathrm{Cm}$, length $38 \mathrm{Cm}$ wide and $28 \mathrm{Cm}$ with selling price of one unit is the compressor tool made for Rp. 930,000,-.

Keywords: Air conditioners, compressors, freon Tubes.

\section{Pendahuluan}

Kompresor adalah mesin atau alat mekanik yang berguna untuk meningkatkan tekanan atau memampatkan fluida gas atau udara. Kompresor pada umumnya menggunakan motor listrik, mesin diesel atau mesin bensin sebagai tenaga penggeraknya. Udara bertekanan hasil dari kompresor biasanya diaplikasikan atau dipakai pada pengecatan dengan teknik spray/air brush, untuk mengisi angin ban, pembersihan, pneumatik, gerinda udara (air gerinder) dan lain sebagainya. Pada saat ini banyak pabrik yang memproduksi kompresor untuk dijual dipasaran, namun harga yang ditawarkan cukup tinggi yaitu mulai dari Rp 1.500.000,-. Kompresor buatan pabrik tersebut juga memiliki kelemahan yaitu jika ada kerusakan kita akan kesulitan dalam perbaikan karena bergantung pada ketersediaan suku cadang buatan pabrik yang sulit didapatkan dan harga suku cadang yang mahal. Untuk itu penulis akan membuat kompresor dengan biaya yang terjangkau dan peralatan dari bahan-bahan yang mudah didapatkan.

Kompresor yang akan dibuat ini memanfaatkan limbah dari kompresor kulkas dan tabung Freon dari Air Conditioner (AC). Adapun kompresor kulkas berfungsi sebagai alat untuk memompa udara yang disimpan pada tabung freon sehingga akan menghasilkan udara yang bertekanan. Kompresor ini memiliki nilai ekonomis yang baik karena biaya pembuatan yang murah dan dibuat dengan memaanfaatkan gabungan peralatan tersebut diatas serta berfungsi sama baiknya seperti kompresor buatan pabrik. Berdasarkan uraian diatas maka penulis membuat tugas akhir dengan judul "Pemanfaatan Limbah Kulkas Dan Tabung Freon Untuk Menjadi Kompresor".

\section{Rancangan Awal Produk}

Dibawah ini adalah gambar rancangan awal Pemanfaatan Limbah Kulkas dan Tabung

Freon: 
Gambar

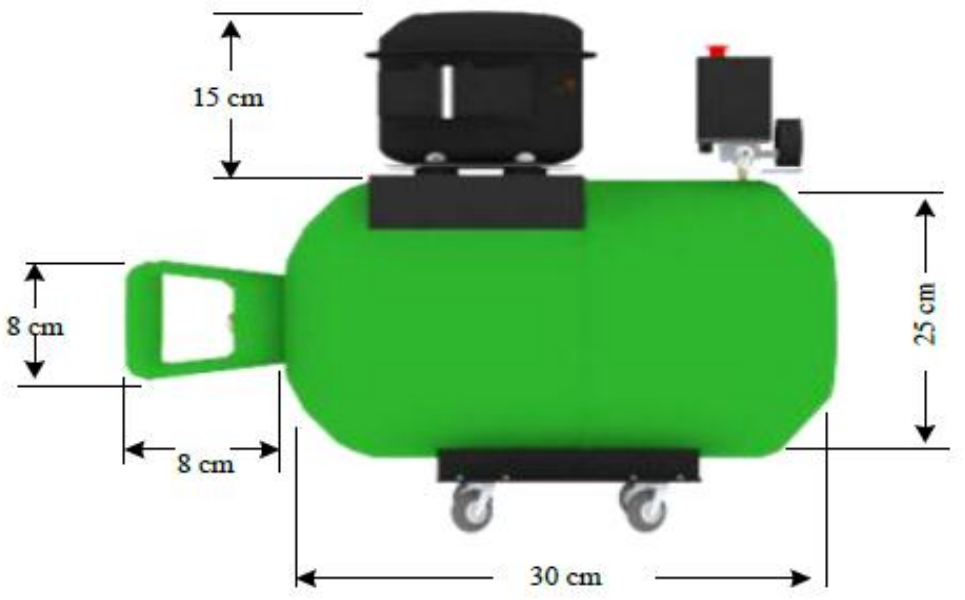

Kompresor dari tabung freon
1.

Freon

Keterangan gambar:

1. Tabung sebagai

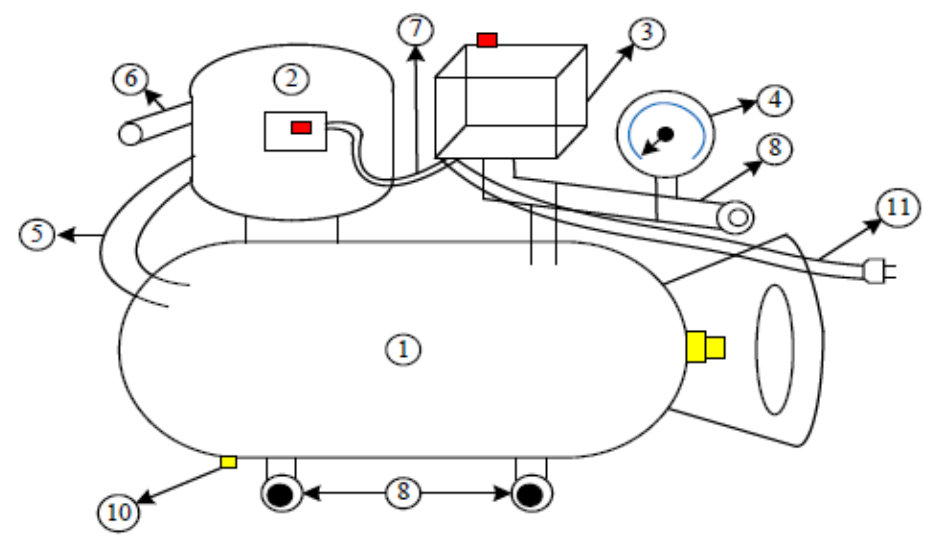

penampung angin.

UNITEX Vol 11 No.1 Januari - Juni 2018 p-ISSN 2089-3957 | e-ISSN 2580-2585 
2. Kompresor Kulkas sebagai motor penggerak utama.

3. Automatis kompresor berfungsi sebagai alat pemutus arus listrik kompresor ketika tabung Freon penuh tekanan angin.

4. Manometer (Presure Gauge) digunakan sebagai penunjuk jumlah tekanan.

5. Katub tekan berfungsi sebagai menyalurkan udara dalam kompresor ke tabung.

6. Katub hisap berfungsi sebagai menghisap udara luar ruangan kemudian diteruskan ke katub tekan.

7. Kabel dari kompresor di sambungkan ke otomatis kompresor.

8. Katub udara keluaran dari tabung Freon.

9. Roda kompresor angin.

10. Katub berfungsi sebagai tmpat pembuangan air yang ada dalam tabung.

11. Kabel steker sumber arus utama Kompresor angin untuk menghidupkan kompresor kulkas.

\section{Metode Penelitian}

Penetian dilakukan di bengkel Rican Service Jl. Jend Sudirman Gg. Lingga Sari No. 56 Kota Dumai, yang dilakukan pada bulan Mei 2017. Objek yang diteliti adalah bagaimana cara pembuatan Kompresor dari tabung Freon yang dapat berfungsi dengan baik. Data primer merupakan data yang diperoleh secara langsung dari pekerja Bengkel yang berada di Jl. Jend Sudirman, Kecamatan Dumai kota, yaitu berupa data Alat-alat kompresor. Data sekunder yaitu data yang diambil secara tidak langsung, Pada penelitian ini data sekunder berupa harga material seperti Harga Kompresor Kulkas bekas, tabung Freon Bekas, Presure gauge, Katub otomatis, Slang angin, ban kecil, besi, Gan penyemprot, dan cat. Dan litaratur pendukung berupa jurnal, dan buku. Pengumpulan data dilakukan dengan cara membaca literatur tentang tabung Freon dan kompresor kulkas yang di peroleh dari internet.

\section{Hasil dan Pembahasan}

Data-data yang dikumpulkan dalam penelitian ini adalah data yang dibutuhkan dalam pengolahan data dan perancangan kompresor dari limbah kulkas dan tabung Freon. Hasil pembuatan kompresor dapat dilihat pada Gambar 2 . Berikut adalah gambar beserta ukuran-ukuran pada kompresor 


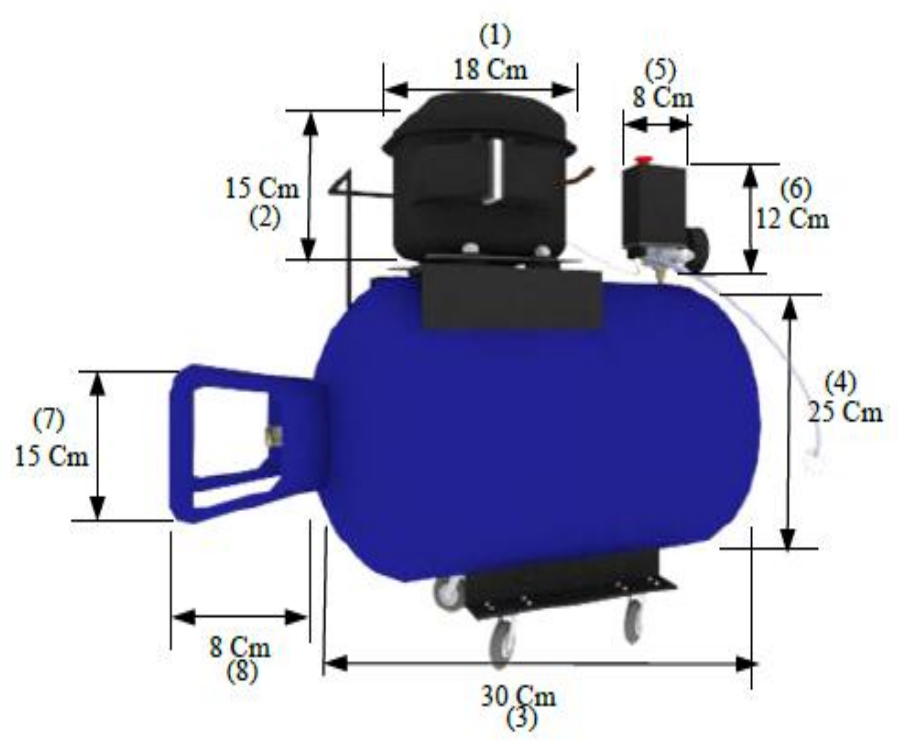

Gambar 2. Perancangan kompresor tampak depan

Keterangan:

1. Ukuran panjang kompresor kulkas $18 \mathrm{~cm}$

2. Ukuran tinggi kompresor kulkas $15 \mathrm{~cm}$

3. Panjang tabung freon dengan ukuran $30 \mathrm{Cm}$

4. Tinggi tabung freon dengan ukuran $25 \mathrm{Cm}$

5. Panjang otomatis kompresor dengan ukuran $8 \mathrm{Cm}$

6. Tinggi otomatis kompresor dengan ukuran $17 \mathrm{Cm}$

7. Lebar tangkai kompresor $8 \mathrm{Cm}$ sebagai pegangan kompresor

8. Tinggi tangkai kompresor $8 \mathrm{Cm}$

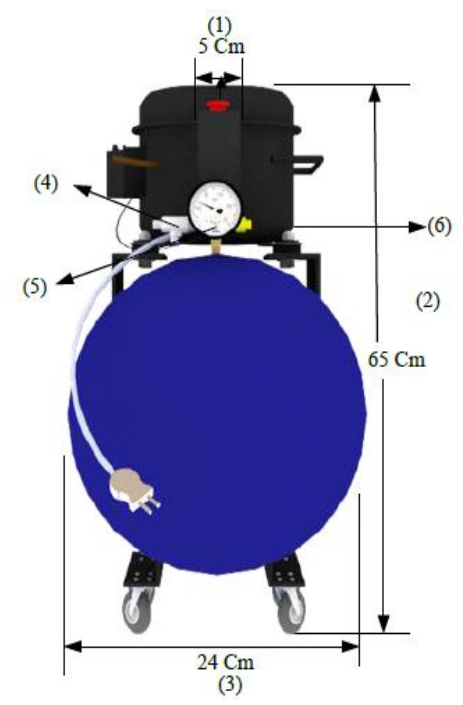

UNITEX Vol 11 No.1 Januari - Juni 2018 p-ISSN 2089-3957 | e-ISSN 2580-2585 
Gambar 3. Perancangan kompresor Tampak kanan

Keterangan:

1. Lebar otomatis kompresor $5 \mathrm{~cm}$

2. Tinggi kompresor angin dengan ukuran $65 \mathrm{Cm}$

3. Ukuran diameter tabung freon $25 \mathrm{~cm}$

4. Pemblok angin yang berfungsi sebagai pemblok angin

5. Pressure Gauge yang berfungsi sebagai penunjuk tekanan dalam kompresor

6. Tembak angin yang berfungsi sebagai penanda angin ketika angin dalam tabung sudah penuh

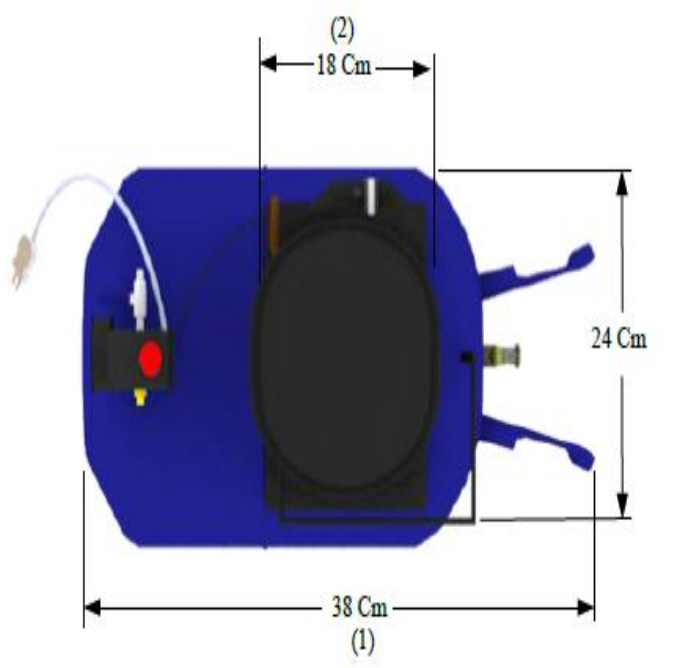

Gambar 4. Perancangan kompresor Tampak Atas

\section{Keterangan:}

1. Panjang compressor dengan ukuran $38 \mathrm{Cm}$

2. Diameter kompresor kulkas dengan ukuran $18 \mathrm{Cm}$

3. Lebar kompresor angin secara keseluruhan $28 \mathrm{Cm}$

Dari hasil pengolahan data bahan dan daftar harga bahan yang dibutuhkan kita bisa menghitung Break Event Point (BEP) dengan perhitungan sebagai berikut:

1. Biaya Tetap

Biaya Sewa Alat $=$ Rp. 100.000

2. Biaya Variabel

Biaya Pembelian bahan $=$ Rp. 675.000

3. Harga pokok Produksi per unit untuk menghitung Harga pokok produksi per Unit adalah Biaya Tetap + Biaya Variabel, maka: 
Harga pokok produksi per Unit $=$ Rp. $100.000+$ Rp. $675.000=$ Rp. 775.000,-

Jadi Harga pokok produksi per unit adalah Rp. 775.000,-

4. Perhitungan Break Event Point Unit adalah:

BEP Unit $=($ Biaya Tetap $) /($ Harga Pokok Produksi - Biaya Varibel Per Unit $)$

BEP Unit $=$ Rp. $100.000 /$ (Rp. 775.000,- Rp. 675.000,-)

BEP Unit $=$ Rp. 100.000,- / Rp. 100.000,-

BEP Unit $=1$

Perhitungan Break Event Point Rupiah adalah:

BEP Rupiah $=($ Biaya Tetap $) /($ Kontribusi Margin Per Unit $/$ Harga Pokok Produksi $)$

BEP Rupiah $=$ Rp. $100.000 /($ Rp. $100.000 /$ Rp. 775.000)

BEP Rupiah $=$ Rp. $100.000 / 0.129$

BEP Rupiah $=$ Rp. 775,000

Perhitungan harga per Unit adalah

Harga Jual per Unit $=$ BEP Rupiah $+($ BEP Rupiah $\times 20 \%)$

Harga Jual per Unit $=$ Rp. $775.000+($ Rp. $775.000 \times 20 \%)$

Harga Jual per Unit $=$ Rp. $775,000+$ Rp 155.000

Harga Jual per Unit $=$ Rp.930.000

Melalui perhitungan BEP di dapat harga setiap satu unit kompresor yaitu sebesar Rp. 930.000,- Dimana BEP rupiah ditambah keuntungan yang ingin diambil yaitu sebesar 20\% dari BEP Rupiah.

\section{Pengujian Kinerja Kompresor}

Pengujian ini bertujuan untuk mengetahui kinerja Kompresor Cara pengujiannya adalah denga mengunakan Ban Sepeda Motor Hasil dari pengujian dapat dilihat pada Tabel 1.

Tabel 1. Pengujian Kompresor

\begin{tabular}{|c|c|c|c|c|c|}
\hline \multirow{2}{*}{ No } & \multirow{2}{*}{$\begin{array}{c}\text { Nama } \\
\text { Kendaraan }\end{array}$} & \multicolumn{2}{|c|}{ Ukuran Ban } & \multicolumn{2}{|c|}{ Kapasitas Angin } \\
\hline & & Depan & Belakang & Depan & Belakang \\
\hline 1 & Motor Revo & $70 / 90(17)$ & $80 / 90(17)$ & 20 Psi & 25 Psi \\
\hline 2 & Motor Karisma & $70 / 90(17)$ & $80 / 90(17)$ & $30 \mathrm{Psi}$ & 32 Psi \\
\hline 3 & Motor Beat & $80 / 90(14)$ & $90 / 90(14)$ & 15 Psi & $20 \mathrm{Psi}$ \\
\hline 4 & Sepeda & & & 9 Psi & 9 Psi \\
\hline
\end{tabular}


Uji coba Kompresor dilakukan pada hari sabtu 16 November 2017 pukul 13.00 WIB di kampus STT Dumai. Uji coba dilakukan sebanyak 4 kali Percobaan dilakukan dengan menggunakan Ban sepeda motor.

\section{Simpulan}

Berdasarkan penelitian perancangan kompresor yang dilakukan peneliti, maka diambil kesimpulan yaitu pemanfaatan limbah kulkas dan tabung Freon ini sangat cocok di gunakan untuk pemakaian pekerjaan yang memerlukan angin, selain bodinya ringan, hemat listrik dan aman dari jangkauan anak-anak. kompresor yang dirancang tekanan anginnya 120 Psi atau 8 bar, dengan kapasitas 8 bar dapat mengisi ban sepeda Motor bebek 3 Unit, Metic 3 Unit dan Sepeda 13 Unit, Lama waktu pengisian 8 bar adalah 10 Menit 11 detik. dan kompresor ini bisa diatur tekanan anginnya sesuai yang diinginkan oleh sipengguna, tinggi kompresor ini 65 $\mathrm{Cm}$, panjang $38 \mathrm{Cm}$ dan lebar $28 \mathrm{Cm}$ dengan harga jual satu unit alat kompresor yang dibuat seharga Rp. 930.000,-

Saran yang disampaikan oleh penulis yaitu perancangan kompresor ini di harapkan fungsi dari alat tersebut dapat dilanjutkan kepada penelitian untuk fungsi-fungsi yang lebih bermanfaat lagi dan perancangan kompresor ini diharapkan dapat dilanjutkan agar memiliki daya tarik yang tinggi terhadap penampilan kompresor ini.

\section{DAFTAR PUSTAKA}

Anzip. (2012). Proses Perencanaan Perawatan Pada Kompresor Flash Gas. Surabaya: ITS Surabaya, Vol.1, No. 1, (2012) 1-5.

Arrasich. (2014). Perhitungan ulang instalasi kompresor cp9560 pada Central Procesing Area (CPA) job pertamina-petrochina east java tuban, Surabaya: ITS Surabaya.

Bernando. (2014). Rancang Bangun Kompresor dan Pipa Kapiler Untuk mesin pengering pakaian sistem pompa Kalor dengan daya $1 \mathrm{pk}$, Departemen Teknik Mesin, Fakultas Teknik, Medan : Universitas Sumatera Utara.

Efendi (2012). Rancang bangun sistem kontrol pada kompresor tekanan udara sebagai pengisi udara untuk ban kendaraan, ITS Surabaya.

Ginting, R. (2009). Perancangan Produk, Yogyakarta: Graha Ilmu

Nofirza. (2012), Perancangan Alat Pemotong Nenas yang Ergonomis untuk meningkatkan Produktivitas, Jurusan Teknik Industri, Fakultas Sains dan Teknologi, Riau: UIN Suska Riau.

Nurmianto, Eko. (2004). Ergonomi Konsep Dasar dan Aplikasinya, Surabaya: Penerbit Guna Widya.

Purba, Immanuel. (2015). Perancangan dan Pembuatan Mesin Pencacah Pelepah Kelapa Sawit. Dumai: Teknik Industri, STT Dumai

UNITEX Vol 11 No.1 Januari - Juni 2018 p-ISSN 2089-3957 | e-ISSN 2580-2585 
Sutalaksana, I,Z, dkk,. (2006). Tenik Perancangan Sistem Kerja, Teknik Industri, Bandung. Sutriadi Randa 2015, Perancangan Alat Kunci Tambahan Pengaman Sepeda Motor Metic dan Bebek, Dumai: Teknik Industri, STT Dumai. 